Pro-Fil (Special Issue) 2021: 23-32

https://doi.org/10.5817/pf21-3-2418

\title{
FUNCTIONALISM AND PERSONAL IDENTITY - THE CASE OF MR. JONES
}

\author{
GUNNAR KARLSEN
}

Department of Philosophy, University of Bergen, Norway, gunnar.karlsen@uib.no

ANNE GRANBERG

Department of Philosophy, University of Bergen, Norway, anne.granberg@uib.no

RESEARCH PAPER • SUBMITTED: 14/10/2021 • ACCEPTED: 21/11/2021

\begin{abstract}
Stanisław Lem's short story Are you there Mr. Jones?, first published in 1955, is set in a courtroom. The plaintiff is Cybernetics Company - a provider of prosthetics - and the defendant is Harry Jones, a race-car driver. It turns out that Mr. Jones, after a series of grave accidents, has had his entire body gradually replaced by prostheses. He is now deep in debt to the provider, Cybernetics Company, which consequently has sued him to reclaim their property. We aim to show that this short story illustrates important philosophical questions concerning personal identity and persistence over time, and that Lem in fact anticipates several of the main insights of functionalism, later introduced by Putnam (1967) and today a main contender for a theory of the mind. If the identity of Mr. Jones is constituted solely by his prostheses' functional role, i.e., their causal relations to input, output and other bodily and mental states, Lem here gives us an early example of causal-theoretical functionalism. This brings us to the next question, implicitly raised by Lem: Is functional identity sufficient for personal identity? Is Mr. Jones the same person as he was before replacing all his body parts? In court, Mr. Jones argues for his continued personhood by appealing to memories from the past. This suggests the view that his persistence as a person depends on some form of psychological continuity, and we will discuss how the case of Mr. Jones relates to views on personal identity.
\end{abstract}

Keywords: Stanisław Lem; functionalism; personal identity

\section{Introduction}

Science fiction stories are often long versions of philosophical thought experiments, which constitute an integral part of philosophy. From Plato's allegory of the cave to Descartes' evil demon, thought-experiments function as windows into the fundamental nature of things, openings that allow us to construct hypothetical situations in order to reveal philosophical insights, even though the frame of the thought experiment might exceed the limit of current technology or even the laws of nature. At its best, science fiction functions in a similar way, giving 
us a glimpse of possible futures (be they utopian or dystopian) as well as posing pressing questions about how technology impacts our world and our view of ourselves. Stanisław Lem's work operates in the borderland between science and philosophy, exploring how our traditional categories and understanding of the world clashes with new technological possibilities - often with both uncanny and hilarious effects.

Lem, who is often credited with foreseeing many current developments like the internet, nanotechnology, virtual reality, audiobooks and smartphones, did not consider himself a science fiction writer, but rather an experimental writer: 'One could simply say that I attempt certain mental experiments and try to create certain situational models' as he expresses it in an interview with Raymond Federmann from 1983. The short story that we will discuss here, 'Are you there, Mr. Jones?', is an example of such a thought experiment. Although only a few pages long, the text contains rich material for philosophical discussion. This story - originally published as 'Czy pan istnieje, Mr. Johns?' in 1955 - is the first work by Lem translated into English and appeared in 1969 in the British-Australian science fiction magazine Vision of Tomorrow. ${ }^{1}$ It has also been adapted into a radio play and later film entitled 'Przekladaniec' ('Roly Poly' in English).

The setting is a courtroom and the protagonists are a judge, an attorney for Cybernetics Company, Mr. Donovan (a representative of said company) and the defendant Mr. Jones, who defends himself. During the case, we learn that the former race-car driver has had several accidents, which has led him to gradually replace all parts of his body - including his brain - with artificial prostheses supplied by Cybernetics Company. Mr. Jones has not been able to pay for these prostheses however, and Cybernetics is now suing in order to regain their property. We also learn that this is not the first court case involving Cybernetics Company and Mr. Jones. The previous case - where Mr. Jones still retained half of his original organic brain - was dismissed because the removal of the prostheses '...would have rendered further life impossible for the debtor.' (55). At present, however, the company claims that since Mr. Jones' last segment of organic brain has been removed and replaced by the 'Genius' model (made by Cybernetics Company), Mr. Jones no longer exists. He is merely a collection of prostheses belonging to Cybernetics. During the comedic back-and-forth between the participants in the courtroom, Mr. Jones makes the point that the attorney and Cybernetics Company are, in fact, making two contradictory claims: 1) That Mr. Jones is no more than 'a collection of artificial organs', and that Cybernetics has a right to have their property returned. 2) That Mr. Jones is guilty of defrauding the company. In arguing simultaneously that Mr. Jones is deceased, and that he 'acts with malice aforethought' and never intended to pay for his replacements, the representatives of Cybernetics Company find themselves in a double bind: Either Mr. Jones is a person - but then he cannot be the property of Cybernetics - as Mr. Jones argues, that would be tantamount to either murder or slavery - or he is in fact only a collection of 'plastic and steel pieces' (56). In the latter case, Mr. Jones is just a machine, not a person, and hence cannot be held criminally responsible or sued.

The story ends with the judge declaring that '[...] since there are some fundamental details which the court must clear up, I hereby adjourn the trial' (57). The judge's befuddlement illustrates the inability of our traditional concepts to account for unforeseen results of technological development, a theme we also find explored in other short stories by Lem, such as 'The Washing

\footnotetext{
${ }^{1}$ https://archive.org/details/Vision of Tomorrow_v01n01_1969-08_SLiV , pp. 55-57. All references to the short story are to this translation.
} 
Machine Tragedy' (1981). While this opens up a wider discussion about the challenges technology represents to our institutions and legislation, we will here focus more narrowly on the ontological issues raised in the short story.

We aim to show that the short story contains rich material for further philosophical discussion and should be included in the recent upsurge on philosophy and science fiction (Schneider 2016, De Cruz et al. 2021). First, we compare the case of Mr. Jones to a functionalist view of mental states, and then use the 'fading-qualia' scenario introduced by Chalmers (1996) to suggest that what may matter in the case of Mr. Jones is not primarily functional identity but rather some form of personal identity. This brings us to the second part, where Parfit's view is introduced in order to discuss what kind of continuity the case of Mr. Jones represents. We end by proposing that the short story itself could be read as a case of the Turing Test. For terminological clarity, where we discuss the different versions of Mr. Jones, we will refer to Mr. Jones as he appears in court as 'Mr. Jones-now' and Mr. Jones as he was originally, before Cybernetics Company started replacing his body parts, as 'Mr. Jones-before'.

\section{Functionalism}

Let us start by looking at functionalism, as a theory of the mind, and how this view relates to the case of Mr. Jones. The main claim in functionalism is that mental states are identified by what they do. A mental state is thus defined by the set of causal relations it bears to sensory stimuli, other mental states, and behavior. This allows functionalism to answer the metaphysical problem of mental states, while being neutral on the ontological problem of what they are 'made of'. Functionalism can thus tell us what, for example, all pain states have in common, without any commitment as to the way pain is realized, be it in a physical or non-physical way. It is important to keep in mind that functionalism is about how mental states can be defined, i.e., what the defining features of a mental state are. This gives functionalism some advantages compared to previous views like behaviorism and identity theory. According to behaviorism, mental states are defined by their dispositions to action, while identity theory defines mental states as (type-)identical to brain states. Functionalism, by contrast, holds the positive claim that a mental state is defined by causal relations to input states (sensory states), output states (behavior) and other mental states and the negative claim that a mental state is not defined in terms of the material substances of which it is composed.

Functionalism was introduced as a theory of the mind by Hilary Putnam $(1960,1967)$ as a response to difficulties facing behaviorism as a scientific theory and the identity theory's problems with explaining the multiple realizability of mental states. Although early antecedent versions of this view can be found in Aristotle and Hobbes (Levin 2018) it was with Putnam's introduction of mental states defined as states in a Turing machine that functionalism found its place in contemporary philosophy of mind. Machine functionalism faces some serious objections (Block and Fodor 1972) and today causal theoretical functionalism, as described above, seems to be the most promising candidate. The main objections to functionalist theories usually start from the requirement of functional identity. Cases like inverted or absent qualia, where two individuals are functionally identical but experientially different, serve as counterexamples to functionalism and are heavily debated (Block 1980). The requirement of identity also makes functionalism a rather demanding view; it is not sufficient for two mental states to be functionally similar in most respects, the view requires that they are functionally identical. 
The short story presents the possibility that Mr. Jones still exists, but is Mr. Jones-now functionally identical to Mr. Jones-before? He stands in court, vigorously arguing the case that he is the same person as he has always been. As the background for the very plot of the text, Mr. Jones' claim clearly assumes a form of functionalism. Each body part replaced by Cybernetics Company apparently performs the same function as the corresponding original body part. However, although Mr. Jones-now appears as functionally identical to Mr. Jones-before on an overall level, there are several passages in the text that indicate a difference between Mr. Jones-before and Mr. Jones-now. When asked by the judge not to interrupt with 'hissing, twittering and gnashing his teeth', Jones replies: 'It isn't me, it's the 'Genius'. It always does that when I'm trying to think hard.' (56), and he goes on to blame the company for bad workmanship:

I shan't go into their defects. I won't say how constantly, whether I'm on my feet or sitting down, eating or sleeping, my head keeps humming, so much that my brother made me move into another room because I kept him awake at night! (ibid.)

And, he continues, it is because:

... these overpriced 'Genius' brains which are nothing more than glorified adding-machines, I have developed an adding mania and have to count railings and cats, poles and pedestrians, and God knows what else! (ibid.)

The short story was first published 3 years ahead of Putnam's first formulation of functionalism and 10 years before functionalism really got traction. In this context, we propose that the basic plot of the short story is based on an antecedent version of causal-theoretical functionalism. In order to make sense of the story told, the reader is necessarily invited to accept the idea that Mr. Jones-now's prostheses are functionally identical to their counterparts in Mr. Jones-before. However, the text puts in doubt whether the prostheses making up Mr. Jones-now actually meet this requirement. So, rather than functionalism being the problem here, one could say that Cybernetic Company has not fulfilled the requirements needed to make functionally identical body parts.

\section{Is Mr. Jones fading out?}

The story of Mr. Jones also parallels the silicon chip replacement thought experiment, originally introduced by David Chalmers (1996) to illustrate the problem of fading qualia. Chalmers asks us to imagine a person whose brain neurons are slowly replaced one by one with silicon

chips that are functionally identical to the neurons. This process presents us with three alternative outcomes:

1. Qualitative conscious experiences (qualia) will disappear suddenly when some particular neuron is replaced.

2. Qualia will gradually fade away.

3. Qualia will remain the same.

In the case of qualia, Chalmers claims that as long as you don't notice the replacement of one particular neuron, together with the unlikeliness that just one neuron will make the difference, alternative 1 is ruled out. The choice between 2 and 3 has been heavily debated. Similar alterna- 
tives are available in the case of Mr. Jones when it comes to whether he can be said to still be the same person. If we replace his body parts one by one with functionally identical parts, we have three possible options:

1. Mr. Jones will disappear suddenly when some particular body part is replaced.

2. Mr. Jones will gradually fade away.

3. Mr. Jones will remain the same.

Alternative 1 seems more plausible here than in the case of qualia, in particular if the whole brain is replaced in one step (or two, as in Mr. Jones' case). This is also the position argued by Cybernetics Company vis-a-vis Mr. Jones. There is a level of irony added here in that Cybernetics claims that the last operation was done out of 'humanitarian' concerns for Mr. Jones' welfare, since his "old brain was not compatible with its new surroundings" - at the same time as their case depends on this last operation being tantamount to killing Mr. Jones. Jones, on his part, accuses Cybernetics Company of intentionally offering him the second hemisphere replacement in order to harvest all the prostheses. That is, if the personhood of Mr. Jones depends on him retaining his original left hemisphere - which the claim that he is now dead implies - one could argue that by their own logic, Cybernetics Company has in fact murdered Mr. Jones with this last procedure.

Alternative 3 is true only if Mr. Jones-now is functionally identical to Mr. Jones before. However, as already discussed in relation to functionalism above, some of his new body parts appear to malfunction so this alternative can be ruled out. But what about 2? The remarks made by Mr. Jones in court about defects in the replaced body parts may not only be taken as an argument against him being functionally identical to Mr. Jones-before, but also as evidence that he is changing as a person, gradually becoming another, which brings us to the question of personal identity: In what way can Mr. Jones-now be said to be identical to Mr. Jones-before?

\section{Personal identity}

Persons persist through time. The question of personal identity is concerned with what makes a person the same over a period of time, often called the problem of persistence. Many views have been proposed here (see Olson 2019 for an overview and discussion), and several of these are alluded to in Lem's text. In the following section we will examine some central theories of personal identity and how they relate to the case of Mr. Jones.

Cybernetics Company seems to argue that Mr. Jones does not exist by appealing to a view where our persistence depends on having the same human body or biology. You are that past or future being that has your body, or that is the same biological organism as you are now:

I should like to repeat the point at issue - that the defendant can not be a defendant at all, since the object over there is nothing but a mechanical construction which is maintaining that it is its own master. In reality, however, [...] the defendant is no longer alive ... (56)

A purely biological form of this view on identity is advocated by Eric Olson (1997). According to his view, we are organisms or animals, and that the persistence of the organism is not in virtue 
of any sort of psychological continuity. Rather, personal identity consists in having the same biological life. One could survive the destruction of all of one's psychological contents and capabilities as long as the human organism remains alive - that is, as long as its vital functions, such as breathing, circulation, and metabolism, continue. This allows for us to exist even if our bodies are in vegetative states.

Cybernetics similarly argues that Mr. Jones no longer exists since his original body is 'scattered over various European race-tracks' and that Mr. Jones-now is only a mechanical copy. Given that organisms are biological entities, and Mr. Jones-now patently is a physical non-biological being, we must concede that if we accept that identity depends on some form of continued biology, Mr. Jones-now clearly cannot be the same as Mr. Jones-before, that is, at least as long as Cybernetics Company's prostheses are mechanical, rather than biological. Biological views like this are controversial and have been challenged using thought-experiments of duplication, originally introduced to the debate as imagined cases of teletransportation (Parfit 1984). In the original example, two new molecule-by-molecule biological copies of one person are made. The possible existence of copies of you on a remote planet challenges our intuitions on identity; and suggests that it cannot solely be based on material identity.

The alternative is to ground our persistence in some form of psychological - rather than biological - continuity. An early version of this view is found in Locke's thought experiment with the prince and the cobbler, who one day wake up and find that their souls have been swapped. In Locke's view, consciousness and memories go along with the soul and the person that used to be the prince now lives on in the cobbler's body, and vice versa. Hence, in this view, memories play a basic role in determining one's identity. While defending himself in court, Mr. Jones argues that he is indeed the same person as before, and in doing so he appeals - at least indirectly - to his previous memories. When he complains about the summing of his new brain and its various malfunctions, these complaints can only be valid against a background of remembered previous experiences of how things used to be. He also recollects episodes earlier in his life, like how he began car racing:

My late father, Lexington Jones — God rest his soul — was the owner of several racing-cars and he gradually instilled in me a love for racing. I first started at the age of seventeen and since then I have taken part in eighty-seven professional races, coming first in sixteen, second in twenty-one, third in ... (57)

In this case, we do seem to have some form of psychological continuity between Mr. Jonesbefore and Mr. Jones-now. But is this continuity sufficient for persistence? We may say that you are psychologically continuous now, with a past or future being, provided that at least some of your current mental states relate to those he or she was in then, by a chain of psychological connections. Normally, such connections are established as a causal chain. In the case of Mr. Jones this raises a question of what happened when the two halves of his brain were replaced. It is not straightforward to assume that the memories in his original biological brain are the causes of the memories now held in his mechanical brain. And if there is a break here in the causal chain there may not be sufficient psychological continuity to claim that Mr. Jones-now is the same person as Mr. Jones-then. 
Here we can make use of Parfit's (1984) view of personal identity where we find a weaker form of psychological continuity, which is applicable to the case of Mr. Jones. Parfit's account of what our identity necessarily consists in can be seen as an elaboration of Locke's account. As mentioned above, Locke suggests that what makes you-now numerically identical with someone existing in the past is memory, the fact that you can remember a lot of what this individual in the past was doing and experiencing. Psychological views like Locke's and Parfit's are often combined with moral responsibility; being the same person over time has normative implications. This can be used to test our intuitions about whether Mr. Jones-now is the same person as Mr. Jones-before. Say that Mr. Jones-before had borrowed 1000 Euro from you. Would we then hold Mr. Jones-now accountable for paying the debt? In the very act of suing Mr. Jones, Cybernetics Company has indirectly answered this question with a 'yes'.

What is new in Parfit's discussion of personal identity is not so much his analysis of what personal identity consists in, as in his claim that identity is not what matters. Parfit starts out by appealing to psychological relations (including memory) which can be obtained over time, and he draws a distinction between psychological connectedness and psychological continuity:

Psychological connectedness: The holding of particular 'direct psychological connections', such as belief, memory, intention, over a period of time.

Psychological continuity: The holding of overlapping chains of strong connectedness. (1984, 206)

Parfit thinks that we should say that what does matter is both psychological continuity and connectedness. To see how these two relations differ, imagine the course of Mr. Jones life within a certain period, say a week. Here, day to day memories will be vivid and strongly connected to one another. If we then turn to Mr. Jones' life in a longer span, say 10 years, strong connectedness will not persist for every single memory and experience. However, Mr. Jones would have particular strong connections of memories and experiences scattered throughout those years. For Parfit, it is the latter which exemplifies the right form of psychological connectedness and continuity and is what truly matters in survival. He calls this kind of psychological continuity and connectedness 'Relation R' (1984, p. 207) and he offers a tripartite distinction among candidates for 'what matters': (1) Relation R with its normal cause; (2) R with any reliable cause; (3) R with any cause. An example of the normal kind of cause is the continuous existence of a brain or, more precisely, those areas of the brain which are the seat of the relevant psychological capacities like memory. But as imagined cases of fission and teletransportation show, the cause of continuous psychology can take far more complicated forms, which leads him to the conclusion that 'what fundamentally matters is Relation R, with any cause' (1984, 287). Such examples also lead to the key insight that given the choice between 1) surviving without psychological continuity and connectedness (Relation R) and 2) dying but preserving R through someone else's future existence, the latter is preferable. Whether it is me that survives teletransportation doesn't really matter; what matters is that there is someone psychologically continuous with me.

The importance of Parfit's view for the case of Mr. Jones thus lies in the insight that what should matter is not that Mr. Jones-now is identical to Mr. Jones-before. Rather, what should matter is just that there is at least one person around who's psychologically connected and continuous with Mr. Jones-before. Given our present technology, that there is someone around who's identical to 
me is the ordinary way of getting what's really important. But thought experiments like Parfit's teletransportation and Mr. Jones in Lem's short story, show us that we confuse personal identity with what really is important. In other words, that survival is not necessarily the same as identity and the right question to ask would be if Mr. Jones-then has survived as Mr. Jones-now. Parfit's notion of "surviving" does not require the original person to be identical to the person that she "survives" as: We can even survive as two different people, without implying that we are these people $(1984,203)$. So, regardless of whether the original Mr. Jones is indeed dead - in the sense that his biological body is gone - he has survived if there is a psychological continuation of him represented by Mr. Jones-now. Although there is discussion about what counts as 'any cause' in Parfit's view (Sidelle 2011), there is no doubt that Mr. Jones-now is more than just a random duplication of Mr. Jones-before.

What Parfit calls quasi-memories (q-memories) may be helpful to answer the question of the relation between Mr. Jones-before and Mr. Jones-now. According to Parfit, q-memories provide us with knowledge of past experiences in the same way that memory does, without presupposing that the rememberer and the experiencer are the same person. A subject $\mathrm{S}$ q-remembers an experience if (1) $\mathrm{S}$ has a belief about a past experience which seems in itself like a memory belief, (2) someone did have such an experience, and (3) S's belief is dependent upon this experience in the same way (whatever that is) $(1984,222)$. Such memories do not presuppose personal identity. Rather, they are memories that are of experiences that someone has had and the memory is causally dependent on that experience. That is to say, this memory need not be your own. Similarly, there are other relations included within psychological continuity (e.g. q-intention, q-recognition, etc.) According to Parfit, he notion of q-memory does not presuppose the continued existence of a person. With the notion of q-memories at hand we can return to the memories of Mr. Jones's past. Mr. Jones-now's memories of his youth are possible q-memories and Mr. Jones-now is therefore a possible continuation of Mr. Jones-before.

While not providing a final answer to the question of whether Mr. Jones exist, the story challenges established intuitions on identity and the concept of a person and triggers new ones. In this respect, the story of Mr. Jones could be compared to the way Daniel Dennett's science fiction tale 'Where Am I?' (1984) boggles the mind. Dennett imagines that he is sent on a bomb defusing mission by NASA, and his out of body adventures - including the destruction of his physical body, copying his brain and separation of brain and body, test the limits of leading theories of personal identity, especially informational patternism. Without providing any conclusive answers, both these stories raise questions about personal identity as well as any sophisticated philosophical thought experiment.

\section{Mr. Jones as a Turing test}

Above we say that Cybernetics argues that Mr. Jones-now 'cannot be defendant at all' since he is nothing but a mechanical construction. This reflects a view where mechanical robots are denied status as persons solely on the basis of their construction and it is precisely this that is sought to be avoided by the Turing test. Famously introduced by Alan Turing (1950) the test is designed to omit irrelevant factors in deciding if a being is intelligent.

In the original Turing test, a human investigator conducts multiple conversations via a text-based interface with two participants, one of which is a machine and another which is human. If the 
investigator cannot determine - based on the ensuing conversation alone - which participant is the machine, then the machine has passed the Turing test. In Turing's case, the test is meant to exclude factors like whether or not the being looks like a human. Turing believed that knowledge of their mechanical construction would predispose us to deny machines human capacities like intelligence, and the test is therefore rigged to eliminate what Turing believed was a form of chauvinism against machines $(1950,451)$.

We will suggest that 'Are you there, Mr. Jones?' is constructed as an imagined Turing test for $u s$ - its readers: It is written in a purely dialogical form, devoid of all descriptions and without giving any access to the inner viewpoints of the characters. Thus, the only foothold we have for ascribing thoughts, motives and feelings to the characters are through their utterances. How do we as readers conclude regarding the identity and personhood of Mr. Jones? As written by Lem, Mr. Jones indeed comes across as a person; his language is personal and informal, his reactions come across as understandable, and he exhibits - at least verbally - a range of emotions from pride to anger, and claims that he is deeply offended by the suggestion that he is anything less than a person. In short, he expresses himself in a manner we as readers easily can identify with: 'Step a little closer mate, and then perhaps I can convince you whether I am alive or not!' (56).

The comical effect of the text is partly due to the contrast between the emotional outbursts of Mr. Jones and the repeated claims by the attorney and representative of Cybernetics Company that he is 'never born', 'no longer alive', 'a collection of artificial organs illegally masquerading as Mr. Jones', 'an automaton' etc. The general sense of absurdity which permeates the text also has another source in the performative - rather than semantic - contradictions the plaintiffs become embroiled in. The representatives of Cybernetics Company are continually addressing, accusing, bickering and arguing with someone they claim does not exist. The absurdity is thus rooted in the incongruence between what the plaintiffs claim and what they in fact $d o$ in their speech acts. On the last page, Lem adds another layer of comedy when Mr. Jones' brother - produced in court in order to vouch for Mr. Jones' identity - also turns out to be a robotic copy.

As the short story ends with the judge declaring the trial adjourned, we, the readers, are also left to ponder the 'fundamental details' that need to be cleared up in the case of the personhood of Mr. Jones.

\section{Bibliography}

Block, N. (1980): Are Absent Qualia Impossible?, Philosophical Review (89), 257-274.

Block, N. - Fodor, J. (1972): What Psychological States Are Not, Philosophical Review, (81) $159-181$.

Chalmers, D. (1996): The Conscious Mind. Oxford University Press.

Dennett D. (1978): Where Am I?, in Brainstorms: Philosophical Essays on Mind and Psychology, Bradford Books, 356-64.

De Cruz, H. - De Smedt J. - Schwitzgebel E. (eds.) (2021): Philosophy through Science Fiction Stories, Bloomsbury Academics. 
Federmann, R. (1983): An Interview with Stanisław Lem, Science Fiction Studies (10)1, [accessed 2021-10-14], available at: < https://www.depauw.edu/sfs/interviews/federman29.htm >

Lem, S. (1969): Are you there, Mr. Jones?, Vision of Tomorrow, 1969:08, 55-57, [accessed 2021-10-14], available at: < https://archive.org/details/Vision_of_Tomorrow_v01n01_196908_SLiV >.

Lem, S. (1981): The Washing Machine Tragedy, The New Yorker, 1981-11-30, 44-45.

Levin, J. (2018): Functionalism, in Zalta (ed.) The Stanford Encyclopedia of Philosophy [online], 2004-08-24, rev. 2018-07-20, [accessed 2021-10-14], available at:

< https://plato.stanford.edu/archives/fall2018/entries/functionalism/ >.

Locke, J. (1975). An Essay Concerning Human Understanding, Clarendon Press.

Olson, E. (1997): The Human Animal: Personal Identity Without Psychology, Oxford University Press.

Olson, E. (2019): Personal Identity, in Zalta (ed.) The Stanford Encyclopedia of Philosophy 2002-08-20, rev. 2019-09-06, [accessed 2021-10-14], available at:

< https://plato.stanford.edu/archives/spr2021/entries/identity-personal/ >.

Parfit, D. (1984): Reasons and Persons, Oxford University Press.

Putnam, H. (1960): Minds and Machines, in Putnam, H. (1975): Mind, Language, and Reality, Cambridge University Press, 362-385.

Putnam, H. (1967): The Nature of Mental States, in Putnam, H. (1975): Mind, Language, and Reality, Cambridge University Press, 429-440.

Putnam, H. (1975): Mind, Language, and Reality, Cambridge University Press.

Schneider, S. (ed.) (2016): Science Fiction and Philosophy: From Time Travel to Superintelligence, Wiley.

Sidelle, A. (2011): Parfit on 'the Normal/a Reliable/any Cause' of Relation R, Mind (120), 735760.

Turing, A. (1950): Computing Machinery and Intelligence, Mind (59) 433-460. 